\title{
Do economicismo à dialogicidade: as contribuições do paradigma da ecologia profunda e da noção de gestão social para a temática da sustentabilidade empresarial
}

\section{From economism to the dialogical: the contributions of the paradigm of deep ecology and the notion of social management in the theme of corporate sustainability}

\author{
Carlos Eduardo Justen ${ }^{1}$ \\ Luís Moretto Neto
}

\section{Resumo}

Este artigo, na forma de um ensaio teórico, ao buscar resposta para a problemática - o que significa planejar estrategicamente para a sustentabilidade? -, procurou evidenciar a possibilidade tanto de uma gestão mais sustentável, pois considerando a interdependência intrínseca entre homem e meio ambiente natural, quanto de uma sustentabilidade mais humana, porquanto construída a partir de uma ação comunicativa, numa relação linguística travada entre sujeitos, não entre sujeito-objeto. Desse ponto de vista, a perspectiva analítica dominante acerca da sustentabilidade foi contraposta com o paradigma da ecologia profunda e com uma noção de gestão coerente - gestão social. Ao final, foram delineados seis caracteres teórico-conceituais capazes de estabelecer um escorço de contribuição ao tema da sustentabilidade empresarial e das estratégias empresariais decorrentes.

Palavras-chave: Sustentabilidade. Gestão social. Estratégias empresariais

\begin{abstract}
This article is set out in the form of a theoretical paper and seeks answers to the following question: what does it mean to plan strategically for sustainability? For this purpose, the article sought to prove the possibility both of more sustainable management, considering the intrinsic interdependence between man and the natural environment, and more human sustainability constructed from communicative actions in a linguistic relationship between subjects rather than between subject and object. From this point of view, the dominant analytical perspective concerning sustainability was opposed to the paradigm of deep ecology and the notion of coherent management - social management. In the end, six theoretical and conceptual characters were delineated that were capable of establishing a foreshortened contribution to the theme of the resulting corporate sustainability and corporate strategies.
\end{abstract}

Keywords: Sustainability. Social management. Business strategies

Texto submetido em 29 de julho de 2012 e aceito para publicação em 13 de agosto de 2012.

1 Mestrando em administração pela Universidade Federal de Santa Catarina - CPGA/UFSC. Endereço: Servidão Leovigildo João Vicente, 25, Sul do Rio, CEP 88140-000, Santo Amaro da Imperatriz-SC, Brasil. E-mail: justencarlos@gmail.com

2 Doutor em Engenharia de Produção pela Universidade Federal de Santa Catarina - UFSC; Professor adjunto da UFSC. Endereço: CAD/UFSC - Universidade Federal de Santa Catarina, Campus Universitário Reitor João David Ferreira Lima, Trindade, CEP 88040970, Florianópolis - SC, Brasil. E-mail: moretto@cse.ufsc.br 


\section{Considerações Iniciais}

A discussão sobre o tema da sustentabilidade, quando situada no âmbito da teoria social crítica, numa análise da modernidade, envolve, por um lado, a identificação e a crítica de uma forma de opressão que extrapola as relações de produção e, por outro lado, a defesa de um novo paradigma sociopolítico fundado menos na riqueza e no bem-estar material e mais na cultura e na qualidade de vida (SANTOS, 1995).

Desde a publicação do relatório intitulado "Os limites do crescimento" (1972) pelo Clube de Roma e a realização da Conferência de Estocolmo (1972) pela Organização das Nações Unidas (ONU), o movimento ecológico ganha importância, e a busca por modelos alternativos de desenvolvimento toma vulto. Afora os radicalismos do "economicismo arrogante", indiferente às limitações da biosfera terrestre, e do "fundamentalismo ecológico", que nada prevê além da exaustão dos recursos naturais e da necessidade de estagnação do consumo (SACHS, 2000), as discussões sobre sustentabilidade necessariamente levam em conta o âmbito organizacional, posto que a organização é o mediador moderno entre o homem e a natureza.

Quando a problemática verve para o âmbito dos estudos organizacionais, a sustentabilidade propicia uma reflexão crítica acerca da epistemologia do conhecimento organizacional, seja porque as práticas empresariais são corresponsáveis pelo iminente colapso dos recursos naturais, tendo em vista a predominância da abordagem do conhecimento e da verdade circunscrita à eficiência financeira, valorada a partir do que se produz (FOURNIER e GREY, 2000), seja porque a sustentabilidade, tomada como valor empresarial, pode servir de instrumento de legitimação para as práticas que justamente geram o colapso ecológico, quando exercida no intento de mascarar o conjunto das externalidades negativas da atividade empresarial sobre o entorno ecológico.

Assim, o enfrentamento conceitual das estratégias empresariais para a sustentabilidade - especialmente diante da inclusão, no âmbito da Rio+20, das empresas no chamado Major Groups e no consequente reconhecimento de sua importância para o desenvolvimento sustentável -, implica, antes de tudo, a discussão e a revisão crítica dos pressupostos nos quais se assenta o paradigma dominante nos estudos organizacionais, visto que ambos, práticas sustentáveis e conhecimento organizacional, são recursivamente interligados. Dissociar essas temáticas implica grave erro analítico e associá-las permite uma práxis mais prudente. Tal associação, construída a partir de duas perspectivas teórico-conceituais específicas - paradigma da ecologia profunda, do lado da sustentabilidade, e gestão social, do lado da Administração empresarial -, possibilitam tanto uma gestão mais holística, pois ecológica, quanto o estabelecimento de práticas empresariais sustentáveis construídas mediante um processo público de deliberação e, portanto, respeitando a verdadeira autonomia humana, fundada na capacidade reflexiva e deliberativa do homem, capaz de "[...] pensar o mundo, de se pensar no mundo, de ter uma atividade racional e calculadora, mas também de pôr em questão a si mesmo e a seu meio ambiente" (GAULEJAC, 2007).

O presente artigo insere-se no contexto da discussão teórico-conceitual de uma gestão mais sustentável, pois considerando a interdependência intrínseca entre homem e meio ambiente natural, e de uma sustentabilidade mais humana, porquanto construída a partir de uma ação comunicativa, numa relação linguística travada entre sujeitos, não entre sujeito-objeto, dotada de uma intersubjetividade capaz de realizar a emancipação humana via interação social. Tal objetivo e as evidentes contribuições que daí decorrem têm em vista a construção de um escorço de resposta à seguinte problemática: o que significa planejar estrategicamente para a sustentabilidade?

A partir do resgate do paradigma da ecologia profunda, presente em Capra (2006), e da sua associação com o paradigma da gestão social (TENÓRIO, 1998, 2006, 2008, 2010), pretende-se demonstrar que a sustentabilidade somente será planejada estrategicamente quando (i) comunidades humanas e comunidades ecológicas forem tratadas de forma recursiva e (ii) essa interdependência for concebida de forma dialógica, em espaços deliberativos "[...] onde todos têm direito à fala, sem nenhum tipo de coação [...]" (TENÓRIO, 2006, p. 1146), pautados por valores como a inclusão, a igualdade, o pluralismo, a autonomia e o bem comum e voltados para o bem comum e o bem viver. 


\section{A Temática da Sustentabilidade Empresarial e os Estudos Organizacionais Tradicionais}

A definição de sustentabilidade mais difundida, também no âmbito dos estudos organizacionais, é a do Relatório Brundtland, fruto da formação, pela ONU, de uma Comissão Mundial sobre Meio Ambiente e Desenvolvimento, que formalizou o conceito de desenvolvimento sustentável como "[...] aquele que atende às necessidades do presente sem comprometer a possibilidade de as gerações futuras atenderem às suas próprias necessidades" (BRUNDTLAND, 1991, p. 46), fundamentado em três pilares: crescimento econômico, equidade social e equilíbrio ecológico (DONAIRE, 1999).

Um elemento central desse enfoque é a necessidade de equilíbrio entre proteção ambiental e desenvolvimento econômico e social, no qual "[...] a exploração de recursos naturais, os investimentos financeiros e as rotas de desenvolvimento tecnológico deverão adquirir sentido harmonioso" (CLARO, CLARO e AMÂNCIO, 2008, p. 291). O desenvolvimento tecnológico, nesse contexto, é orientado para duplo empreendimento: metas de equilíbrio com a natureza e de incremento da capacidade de conservação ecológica dos países em desenvolvimento, cujo déficit é crônico diante dos problemas sociais e da histórica deficiência administrativa e financeira.

Não obstante os notáveis avanços em tal conceituação e o fato per si desse assunto passar a ser objeto de preocupação em fóruns globais de deliberação, o conceito do relatório Brundtland vem sofrendo, no mínimo, duas críticas: a manutenção da ênfase econômica, uma vez que o esgotamento dos recursos naturais é reconhecido apenas pelo potencial que possui para retardar ou obstruir o crescimento econômico (GOULART, 2006), e a preservação de uma relação colonialista entre os países, visto que, das recomendações da comissão, caberia aos países desenvolvidos a oferta de soluções tecnológicas e financeiras que viabilizassem um novo padrão de desenvolvimento, enquanto aos países em desenvolvimento tão somente restaria o papel de manutenção dos recursos ecológicos, usando da tecnologia ofertada pelos países mais desenvolvidos (OLIVO e MISOZKY, 2003).

No debate acadêmico sobre o tema, duas correntes principais de interpretação dominam as discussões, ambas fundadas na Ciência Econômica. A primeira, denominada Economia Ambiental, considera que os recursos naturais não representam, a longo prazo, limite à atividade econômica. A noção implícita é a de que a finitude dos recursos naturais pode ser superável indefinidamente pelo progresso científico e tecnológico, capaz de criar artifícios que permitam ao sistema econômico migrar de uma base de recursos para outra. Essa mudança da base de recursos se daria por intermédio dos mecanismos de mercado - a escassez de dado recurso, ao inflar seu preço, geraria uma diminuição de seu consumo e a consequente substituição por outro recurso mais abundante.

A segunda, chamada Economia Ecológica, defende que a finitude dos recursos naturais constitui restrição absoluta à expansão do sistema econômico. Apesar do aumento de eficiência advindo da utilização da tecnologia, a sustentabilidade do sistema econômico no longo prazo só é possível, para essa corrente, mediante a estabilização dos níveis de consumo. Tanto a corrente da Economia Ambiental quanto a da Economia Ecológica tratam do tema da sustentabilidade a partir dos imperativos econômicos, em termos de crescimento da economia e dos prováveis limitadores ecológicos a esse crescimento.

Tendo em vista que as discussões acerca de desenvolvimento e consumo sustentável não podem prescindir das atividades produtivas, a discussão sobre sustentabilidade naturalmente aportou nos estudos organizacionais (VALLE, 2002). Da mesma forma que no tratamento dado ao tema pelo Relatório Brundtland e outros fóruns posteriores de discussão, a temática da sustentabilidade empresarial também recebeu roupagem pretensamente multidimensional, com conteúdo, porém, fortemente econômico, fato reforçado diante da carga epistemológica positiva e instrumental presente no management.

Isso porque, apesar da ausência de consenso sobre o significado atribuído à sustentabilidade (JACOBS, 1995; CLARO, CLARO e AMÂNCIO, 2008), há concordância em relação às dimensões que compõem o termo sustentabilidade, a chamada tripple bottom line - econômica, ambiental e social. A dimensão 
econômica abrange tanto a atividade econômica formal quanto a economia informal, encampando toda a atividade produtiva. A dimensão ambiental ou ecológica preocupa-se com o impacto das atividades empresariais sobre o meio ambiente, incluindo a ecologia, diversidade do habitat, flora, fauna, qualidade do ar e da água, proteção da saúde humana e conservação e administração de recursos naturais. Implica, grosso modo, além do monitoramento, a análise do ciclo de vida do produto e a administração integrada da cadeia de produção. A dimensão social evidencia os aspectos sociais relacionados às qualidades dos seres humanos, como suas habilidades, dedicação e experiências, nos âmbitos interno e externo da organização (SPANGENBERG e BONNIOT, 1998; ALMEIDA, 2002; GROOT, 2002).

O surgimento do pensamento ecológico e o posterior tratamento dado ao tema da sustentabilidade, em especial diante das pressões de parte da sociedade, materializadas por uma consciência ecológica, e a organização de movimentos sociais reivindicatórios, fizeram alterar o ambiente político-social e trouxeram reflexos para a atividade empresarial (CALLENBACH, 1993). As empresas reconheceram a importância da responsabilidade socioambiental, em muito devido à melhoria da imagem institucional e aos benefícios econômico-financeiros daí decorrentes (DONAIRE, 1999).

Características de uma sustentabilidade que permeie um desenvolvimento econômico alternativo, como a endogenia, a autossuficiência, a orientação para as necessidades e não o incentivo ao consumo, e a implementação de mudanças institucionais, como as pregadas por Sachs (2000), quase não são consideradas quando a temática é abordada no âmbito empresarial, surgindo com força apenas em discussões, i.e., sobre desenvolvimento local e economia solidária, locus em que a atividade empresarial perde o protagonismo ante as formas comunitárias e territoriais de organizacional sociopolítica.

O objetivo de maximização do lucro, portanto, permanece reificado, sendo apenas compatibilizado com a necessidade de estabilidade financeira no longo prazo. Os elementos sociais, políticos e culturais, intervenientes ao tema da sustentabilidade, são considerados na medida em que propiciem a continuidade da racionalidade econômico-instrumental. A dominação do homem sobre a natureza (SANTOS, 2007), assim, permanece inalterada, e os imperativos ecológicos são tomados apenas na medida em que ocasionem obstrução à lucratividade e ao predomínio da atividade empresarial sobre as demais formas de organização social.

Defende-se aqui que a apropriação do termo sustentabilidade à atividade empresarial, marcada pela perspectiva economicista, é deturpada pelo matiz epistemológico predominante nos estudos organizacionais, e que o tratamento analítico adequado do tema terá orientação apropriada, quando alternativas ao mainstream dominante - denominado, para a discussão travada, como paradigma da incompletude autoritária - forem contrapostas, e uma concepção menos fundamentada em imperativos econômicos for levada seriamente em consideração. O paradigma da incompletude autoritária é composto, tendo em vista o interesse para a problemática esposada, por três pilares - interiorização autoritária, teleologia da organização e colonialismo intelectual.

O primeiro dos pilares é a interiorização autoritária. Ao conceber a organização como objeto de estudo, a

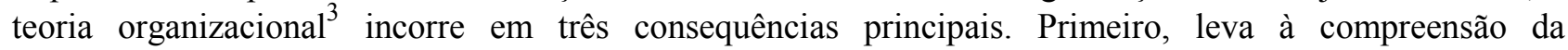
organização como uma entidade única, unidimensional e autônoma em si mesma, afastando de si a recursividade com o entorno ecológico envolvente e a crítica sobre qual concepção de organização realmente existente e, para além disso, almejada. Segundo, leva a crer que organização é uma estrutura social cuja formação e composição é homogênea, negando a condição plural dos sujeitos, enquanto sujeitos de suas histórias, ocultando grande parte das relações de poder e de dominação constituídas, e descaracterizando a historicidade e a subjetividade que identificam a organização enquanto fenômeno político-social. A organização não é composta por uma voz, mas por várias identidades, necessidades e esperanças, o que também leva ao questionamento da legitimidade daquele que critica - seria ele legítimo representante dos oprimidos, silenciados e esquecidos? Por fim, ocorre, como afirma Reed (1998), um distanciamento de

${ }^{3}$ Teoria organizacional é uma denominação imprópria, pois leva a crer na existência de um corpo sólido e sistemático de conhecimentos sobre organização. A pluralidade dos estudos organizacionais aí não se faz representada. 
aspectos como justiça, igualdade, democracia e liberdade, justamente pela postura acrítica e não histórica decorrente das duas primeiras consequências.

A crítica embutida nesse pilar envolve também a contestação de dois outros aspectos: a visão limitada do homem e, paradoxalmente, o viés antropocêntrico dos estudos organizacionais. O homem, na mainstream organizacional, é lido como um ser inteiramente biológico e, nos aspectos ligados e interessantes à performatividade, como fenômeno psicossocial. Assim, as necessidades humanas seriam naturais, dadas, e não como construção e interpretação histórica e socialmente situadas. Bastaria, assim, como apregoam os teóricos "humanistas" - Maslow, McGregor, Herzberg e outros -, satisfazer um conjunto fixo de necessidades para promover a satisfação no trabalho e, por óbvio, a maior produtividade.

Embutida nessa concepção, encontra-se o viés antropocêntrico dos estudos organizacionais, que, a partir dessa concepção limitada de homem, em conjunto com a dicotomia positivista ser humano/natureza, compreende o primeiro como acima ou fora da segunda, a qual possui mero valor de uso. O homem deixa de ser concebido como um ser ecológico, imbricado no meio ambiente natural, um constituinte do outro, tratado de forma dissociada das experiências vividas pelas pessoas em seu cotidiano, como já apontou Chanlat (2006), com o adicional de que tais experiências constituem uma rede de relações desenvolvidas no ambiente ecológico.

O segundo pilar representa a teleologia da organização. Trata-se, em verdade, de uma concepção teleológica que forneceu à realidade da vida humana associada não só aos subsídios ideológicos e discursivos para a construção e manutenção da superioridade, imprescindibilidade e do caráter insubstituível da organização enquanto unidade econômica de produção, mas também para a ampliação de sua autoridade e de seus valores aos demais enclaves humanos.

Os subsídios ideológicos e discursivos necessários à consolidação da concepção teleológica de organização jungem-se às noções de que (i) o progresso social é consequência direta dos aumentos sucessivos na produtividade econômica que, por sua vez, decorre da intensificação tecnológica, planejada e implementada sob os auspícios do management (PAULA, 2007); (ii) as organizações são dotadas de uma virtude moral, pois compatibilizariam o individual e o coletivo em decisões racionais que melhorariam a condição intelectual, econômica e social do homem moderno; (iii) as organizações representariam o locus ideal de exercício da razão científica, liberando o homem das amarras da tradição e do pensamento teocrático que estagnaram a evolução humana durante tantos séculos; (iv) as organizações necessitariam de uma condução técnica, profissional e planejada, cabendo aos gerentes essa responsabilidade; (v) tais gestores estariam respaldados, em sua atividade, por fundamentos ontológicos e epistemológicos. Os primeiros centrados na capacidade de tradução e de previsão das incertezas do mundo real, e os segundos pela encarnação do conhecimento de perícia necessário para essa tarefa.

Com o advento do capitalismo industrial, a denominada sociedade organizacional emergiu como representativa da razão, liberdade, justiça e progresso material. Como Reed (1998) destaca, ao servirem como instrumento de coordenação entre interesses individuais e processos decisórios coletivos, as organizações garantiriam tanto a ordem e o progresso sociais quanto a liberdade pessoal. Desta feita, a organização formal tornou-se o modelo dominante na sociedade contemporânea, e o padrão de racionalidade a ela inerente tornou-se o padrão cognitivo geral.

A partir dos anos 80, com o capitalismo neoliberal, a teleologia da organização foi intensificada pelo movimento gerencialista e pelas inúmeras reformas de Estado dele decorrentes, irradiadas para o resto do mundo pelo governo Thatcher (1979-1990), no Reino Unido, e pela administração Reagan (1981-1989), nos Estados Unidos. Os princípios e valores preconizados pelo management foram cooptados pela arena política e espraiaram-se para a Administração Pública e a esfera social. A lógica da organização tornou-se universal, e o homem passou a ser avaliado em termos de sua compatibilidade com a sociedade organizacional, ou seja, em relação à função técnica que aí desenvolve e dos resultados que gera a partir do seu trabalho. 
A influência do neoliberalismo, aliás, fez-se de forma bastante acentuada, alçando o princípio do mercado a regulador da vida humana associada: à economia dirigida exclusivamente pelos preços de mercado (POLANYI, 2000), à valoração das ações humanas pela lei do valor econômico, à relação sujeito-objeto mediada pela utilidade financeira e à ênfase na eficiência produtiva, performativa.

Todavia, paradoxalmente, ao mesmo tempo em que é intensificada, a teleologia organizacional começa a evidenciar sinais de desgaste. O corpus discursivo da superioridade técnica e da virtude moral das organizações passa a ser confrontado com uma realidade permeada por desigualdades socioeconômicas, desfragmentações político-culturais e esgotamento da biosfera, muito embora a incompletude autoritária dos estudos organizacionais, em especial nos três pilares já discutidos, evite a todo custo demonstrá-la.

A trinca aberta no bloco até então sólido da teleologia da organização está ligada, inconteste de dúvidas, à derrocada do projeto emancipador da modernidade, que, segundo Santos $(1995,2008)$, ao convergir para o capitalismo, oportunizou, de um lado, a supremacia do mercado em detrimento do equilíbrio entre comunidade, Estado e mercado, e, de outro lado, o predomínio da ciência e da técnica em detrimento do equilíbrio entre literatura/artes, direito e ciência/técnica.

O terceiro e último pilar da incompletude autoritária pode ser denominado de colonialismo intelectual e envolve a problematização de quem produz o conhecimento organizacional válido, em que contexto e para quais destinatários, ou seja, o interesse pela geopolítica do conhecimento, tradicionalmente subjugada pela mainstream do management, diante do reposicionamento da esfera política para além de suas fronteiras, como já destacado anteriormente no pilar da refração semântica. Por colonialismo intelectual, entendem-se as relações desiguais, do ponto de vista epistemológico, entre duas ou mais partes, que caracterizam a pretensa inferioridade de uma parte em relação à outra.

Boyacigiller e Adler (1991) demonstram que, do ponto de vista sócio-histórico, têm-se a hegemonia e a universalidade do conhecimento organizacional norte-americano, decorrente da proeminência militar, política e econômica do pós-guerra ianque, com a consequente importância das escolas e periódicos de gestão daquele país. Tal hegemonia foi moldada em um contexto histórico particular - décadas de 30 a 50 e, especialmente, a Segunda Guerra Mundial -, na qual os Estados Unidos alcançaram o status de novo centro de pesquisa nos campos altamente prestigiados das ciências naturais (WHITLEY, 1984).

Naturalmente, o sucesso dos métodos e paradigmas de pesquisa nas ciências naturais, fundamentadas em pesquisas quantitativo-experimentais, chegou à Administração e aos estudos organizacionais e, devido à supremacia na geopolítica mundial, espraiou-se pelo resto do globo. Dois elementos garantiram o sucesso expansionista do conhecimento organizacional norte-americano: (i) as instituições de ensino norteamericanas, que exerceram controle direto sobre o processo de criação e consolidação do ensino e da pesquisa acadêmicas em outras partes do mundo, mediante, por exemplo, missões técnicas e intercâmbio de docentes na Europa e no Brasil, produzindo e difundindo as modernas técnicas e conhecimentos em Administração; e (ii) as multinacionais norte-americanas, que desenvolveram a noção da administração ensinada e profissional, nos moldes das escolas de gestão norte-americanas. Trata-se, portanto, de um sistema hegemônico recursivo e autossustentável.

As consequências do colonialismo intelectual para os estudos organizacionais envolvem o universalismo e o exclusivismo de uma ontologia e de uma epistemologia específicas. A ontologia a ser retratada é a realidade das grandes organizações complexas, intensivas em capital, conhecimento e tecnologia, circundadas por um ambiente incerto que exige a aplicação de métodos científicos de previsão e de um perfil profissional empreendedor e instrumentalista. A epistemologia decantada é a da quantificação, financeirização, decomposição e sintetização de elementos, inclusive humanos, sob o amparo da neutralidade dos valores científicos. No campo do ensino e da pesquisa, a Administração e a gestão predestinam-se, nesse ideário, a garantir a produtividade organizacional, numa abordagem do conhecimento e da verdade circunscrita à eficiência financeira. Para tanto, o homem, enquanto recurso de produção, deve ser adaptado ao sistema produtivo, tanto no âmbito ideológico quanto no das operações de trabalho. 
No Brasil, o colonialismo intelectual traduz-se, primeiro, na importação de tecnologias de gestão norteamericanas, em tradução e adaptação neutralizada e higienizada de valores, sem preocupação com a adequação ao contexto local. Segundo, na descaracterização e, principalmente, na desconsideração de um modo brasileiro de gerenciar e de estudar as organizações locais, cuja tendência é o empobrecimento da rica variedade cultural e histórica da realidade brasileira. Os estudos organizacionais deixam de refletir a pluralidade da vida real e dela se aproximar, constituindo-se ele próprio uma realidade vívida, sociologicamente falando.

Essa tendência começará a ser revertida quando os estudos organizacionais brasileiros se voltarem a uma pluralidade compreensiva, tanto epistemológica, ao reconhecer o valor do senso comum, das práticas e vivências locais que representam a identidade do ser humano, quanto sociocultural, ao fornecer os elementos para a constituição da emancipação de grupos e sujeitos expostos ao jugo do capital neoliberal.

No âmbito da produção e transmissão de conhecimento em Administração e das práticas de gestão, o paradigma da incompletude autoritária faz predominar uma perspectiva estratégica de educação. Tal perspectiva pode ser concebida como um imperativo que intenta produzir ou transmitir conhecimentos e práticas direcionados para uma produção valorada em termos econômicos, isto é, na relação meios-fins, na qual o mínimo de entradas produz o máximo de saídas. Essa educação estratégica vai de encontro a uma pedagogia da autonomia (FREIRE, 2011), pois apenas se ocupa da transferência de conhecimentos, deixando de criar as possibilidades individuais e coletivas de sua construção. Destitui o homem do papel de sujeito de sua própria educação, exclui do processo de aprendizagem a interação com o meio natural e social e fracassa no cumprimento da função social do processo educativo.

É nesse quadro ontológico e epistemológico que se procura discutir e produzir conhecimentos sobre sustentabilidade empresarial. Como já delineado, o resultado é a apropriação de uma perspectiva particular de sustentabilidade, de viés econômico e que trata os aspectos cultural, político e social apenas em consideração aos reflexos que ocasionam sobre a preservação da rentabilidade econômico-financeira. Advogam-se, aqui, duas alternativas possíveis à resolução de tal impasse. Primeiro, a apropriação de correntes de pensamento mais coerentes com a complexidade e interdisciplinaridade do tema e, segundo, a construção de alternativas ao pensamento organizacional dominante. A próxima seção procurará estabelecer um escorço para ambas as orientações - o paradigma da ecologia profunda de Capra (2006) e a noção de gestão social, fundada na perspectiva habermasiana da ação comunicativa.

\section{O Paradigma da Ecologia Profunda e a Gestão Social}

Como contraponto à perspectiva economicista de sustentabilidade, apropriada pelos estudos organizacionais e aplicada no âmbito empresarial, defende-se a relevância do paradigma da ecologia profunda. Esse paradigma, de ponto de vista epistemológico, rebela-se contra a visão da vida e da sociedade como uma luta competitiva e contra a fé no progresso material ilimitado, a ser obtido por meio do crescimento econômico e tecnológico (CAPRA, 2006).

O paradigma da ecologia profunda foi fundado, no início dos anos 70, pelo filósofo e ecologista norueguês Arne Naess, no âmbito da Escola de Oslo. A premissa elementar defendida por esse paradigma é o reconhecimento da interdependência inerente de todos os fenômenos e do fato de que, enquanto indivíduos e sociedades, todos estamos inseridos nos processos cíclicos da natureza (CAPRA, 2006). Em outras palavras, não há predomínio de qualquer perspectiva particular, tão somente a existência de um pensamento ecológico, que percebe o mundo vivo como uma rede inseparável de relações. O Quadro 1 demonstra a comparação entre a ecologia profunda e o paradigma economicista da sustentabilidade. 


\section{Quadro 1}

\section{Paradigmas ecológicos}

\begin{tabular}{|c|c|}
\hline Paradigma economicista & Paradigma da Ecologia profunda \\
\hline $\begin{array}{c}\text { Domínio sobre a natureza } \\
\text { Meio ambiente como recurso }\end{array}$ & $\begin{array}{c}\text { Harmonia com a natureza } \\
\text { Natureza constituída por seres vivos com direitos à } \\
\text { existência independente de seu valor de uso }\end{array}$ \\
\hline Objetivos materiais/crescimento econômico & Objetivos não materiais/sustentabilidade ecológica \\
\hline Recursos naturais ilimitados & Recursos finitos \\
\hline $\begin{array}{c}\text { Soluções baseadas exclusivamente na tecnologia } \\
\text { avançada }\end{array}$ & $\begin{array}{c}\text { Soluções adaptadas a cada situação e ecossistema } \\
\text { Necessidade básica/reciclagem }\end{array}$ \\
\hline Centralização/grande escala & Descentralização/pequena escala \\
\hline Autoritarismo/estruturas repressivas & Estruturas democráticas/participação social \\
\hline
\end{tabular}

Fonte: adaptado de Sylvan (1985) apud Redclift (1987).

A ecologia profunda não dissocia o homem ou qualquer outro fenômeno vivo, social ou material do meio ecológico envolvente. Nesse sentido, deixa de ser antropocêntrica, isto é, de conceber e tratar o ser humano ou as organizações humanas em relação assimétrica com o meio ambiente. Ainda, reconsidera o tratamento dado ao meio ambiente, não mais como mero valor de uso, mas como integrante da própria vida humana (CAPRA, 2006).

Para Capra (2006), o paradigma da ecologia profunda fornece um arcabouço conceitual para a interligação entre comunidades ecológicas e comunidades humanas, tendo em vista que ambas são formadas pelos mesmos princípios básicos de organização: (i) a interdependência - todos os membros de uma comunidade, ecológica ou humana, estão interligados por uma vasta e intricada rede de relações, e cada membro em particular detém suas propriedades essenciais e, de maneira geral, sua existência justamente por causa dessa rede de relações; (ii) a natureza cíclica dos fenômenos, do que decorrem os laços de realimentação dos elementos da rede; (iii) a parceria, sendo que os intercâmbios cíclicos que ocorrem na rede de relações são sustentados por uma cooperação generalizada; e, por fim, (iv) a flexibilidade, capaz de levar a rede sistêmica ao equilíbrio diante de um desvio indevido ou induzido (CAPRA, 2006).

A modificação de uma perspectiva economicista para outra, ecológica, envolve não apenas um alargamento de percepções e modos de pensar, mas também uma radical revisão de nossos valores. De um pensamento autoafirmativo, racional, analítico, reducionista e linear, passa-se a um pensamento integrativo, intuitivo, holístico, não linear. De uma abordagem normativa expansionista, competitiva, quantitativa e dominadora, passa-se a uma normatividade conservadora, cooperativa, qualitativa e de parceria (CAPRA, 2006).

Meio ambiente e natureza humana se revelam similares do ponto de vista analítico e, por conseguinte, a maneira mais coerente de tratamento e aproximação em relação à natureza não é "[..] por meio da dominação e do controle, mas sim por meio do respeito, da cooperação e do diálogo" (CAPRA, 2006, p. 158).

Nesse ponto, importa perguntar qual gestão possui esses requisitos, de forma que reúna as condições de planejar estrategicamente uma sustentabilidade que deixa de ser apenas economicista para constituir-se verdadeiramente ecológica e humana. A interface com a gestão social, uma das alternativas de gestão 
possíveis, resta iniciada e o esforço, em decorrência, deve ser orientado ao aprofundamento desse modo de gestão.

Gestão social, para os propósitos deste trabalho, é caracterizada como "[...] processo gerencial dialógico onde a autoridade decisória é compartilhada entre os participantes da ação [...]" (TENÓRIO, 2008, p. 40), e que "[...] procura atender às necessidades de uma sociedade, região, território ou sistema social específico, quer vinculado à produção de bens quer à prestação de serviços" (TENÓRIO, 2006, p. 1147).

Nesse sentido, o significado adotado associa a gestão social, predominantemente, à possibilidade de gestão democrática e participativa, seja no espaço público ou privado. Para Tenório (2010), a gestão social "[...] é uma tentativa de não pautar os processos decisórios exclusivamente pela ótica da competição, do mercado [...] (p. 58), mas sim "[...] por meio de cursos de ação compreensivos, voltados para o bem comum e o para o bem viver" (p. 58).

Trata-se, assim, de "[...] espaço privilegiado de relações sociais onde todos têm direito à fala, sem nenhum tipo de coação [...]" (TENÓRIO, 2006, p. 1146), pautado por valores como a inclusão, a igualdade, o pluralismo, a autonomia e o bem comum. No sentido adotado, portanto, a gestão social constitui-se em possibilidade concreta de gestão democrática participativa (TENÓRIO, 2008) na definição dos problemas e das soluções vivenciados por uma comunidade ou organização específica. Representa alternativa, passível de aplicação em qualquer enclave organizacional e social, ao mainstream dominante no pensamento administrativo e organizacional, de cunho gerencialista, com marcado teor positivista e instrumental - a gestão estratégica.

As categorias teórico-conceituais definidoras da gestão social estão dispostas no Quadro 2.

Quadro 2

\section{Categorias teórico-conceituais da Gestão Social}

\begin{tabular}{|l|l|}
\hline Objetivo & Interesse coletivo de caráter público \\
\hline Valor & Interesse público bem compreendido \\
\hline Racionalidade & Substantiva/Comunicativa \\
\hline Protagonista & Sociedade civil organizada \\
\hline Comunicação & Dialógica \\
\hline Processo decisório & Descentralizado, emergente e participativo \\
\hline Operacionalização & Social, parcerias e redes intersetoriais \\
\hline Esfera & Todos os enclaves sociais \\
\hline Autonomia e poder & Iguais condiç̃̃es de participação \\
\hline
\end{tabular}

Fonte: Moretto Neto; Garrido e Justen (2011).

Cançado (2011) adiciona, ainda, ainda, as seguintes categorias teóricas da gestão social: sustentabilidade, solidariedade, esfera pública, democracia deliberativa, ação racional substantiva, comunidades de prática, intersubjetividade e emancipação. Esse conjunto normativo de categorias identifica a gestão social, portanto, com o processo decisório coletivo, livre de distorções comunicativas, "[...] baseada na inteligibilidade da 
linguagem, na dialogicidade e no entendimento esclarecido como processo, na transparência como pressuposto e na emancipação enquanto fim último" (CANÇADO, TENÓRIO e PEREIRA, 2011, p. 681).

Ancorado nos conceitos de racionalidade substantiva de Guerreiro Ramos, na teoria crítica da Escola de Frankfurt e, muito especialmente, em Jürgen Habermas e sua noção de ação comunicativa, Tenório (2005, 2008) caracteriza a gestão social por meio do duplo eixo fundamental composto por cidadania deliberativa e agir comunicativo.

Por intermédio da cidadania deliberativa, entendida como a "[...] legitimidade das decisões [que] deve ter origem em processos de discussão orientados pelos princípios da inclusão, da igualdade participativa, da autonomia e do bem comum" (TENÓRIO, 2008, p. 41), a gestão social estaria capacitada a servir como elo entre a sociedade civil organizada, o Estado e o mercado, sendo a primeira protagonista da relação. Seria, assim, um processo participativo, baseado no diálogo e na inclusão.

Mediante o agir comunicativo, de Habermas, por sua vez, a gestão social centra-se em uma linguagem de entendimento, haja vista que, nela, "[...] a verdade é a promessa de consenso racional, [...] não é uma relação entre o indivíduo e a sua percepção de mundo, mas sim um acordo alcançado por meio da discussão crítica [...]” (TENÓRIO, 1998, p. 126).

Desta forma, no conceito de gestão social aqui assumido, é possível apontar as características temáticas. Em primeiro lugar, com forte influência de Habermas, tem-se o processo decisório coletivo, afastado de coerção externa e impositiva, baseado na argumentação, no entendimento e no diálogo. Em segundo momento, percebe-se a transparência, do que decorre a necessidade de a linguagem ser acessível a todos os participantes. Por fim, vislumbra-se, como resultado, a emancipação do homem, tendo em vista o amadurecimento dos atores envolvidos, decorrente da participação efetiva no processo decisório (OLIVEIRA, CANÇADO e PEREIRA, 2010).

A gestão social, como já delineado, tem como fundamento epistemológico a perspectiva habermasiana. Em sua "Teoría de la acción comunicativa" (1987), Habermas traz o conceito de racionalidade comunicativa, um tipo de razão efetivado intersubjetivamente no decorrer do processo de interação dialógica dos atores envoltos em determinadas situações. Busca, nesse sentido, recuperar o projeto inicial da Escola de Frankfurt, tratando de estabelecer uma alternativa para a emancipação por intermédio da razão. Muito embora a primeira geração da Escola de Frankfurt não negasse a razão como instrumento de emancipação, os termos exclusivamente denunciatórios delineados por Horkheimer, Adorno e Marcuse não propunham alternativa propositiva em que razão e emancipação passassem a constituir caminho comum. A contribuição principal de Habermas parece ter sido, desta forma, o redirecionamento da teoria crítica para a razão emancipatória (FREITAG, 1986; ASSOUN, 1991; MATOS, 1993; VIZEU, 2005).

Habermas concebe a ação social a partir da interação comunicativa, isto é, trata esta última como tipo ideal de ação social (FORESTER, 1994), marcada pelo duplo processo de (i) interpretação negociada de uma definição comum da situação e (ii) do entendimento linguístico daí decorrente (HABERMAS, 2003). Na ação comunicativa, os participantes, dentro de um procedimento argumentativo, estabelecem acordo comum sobre questões vinculadas à verdade, justiça e autenticidade. Esse acordo, formado com base numa pretensão de validade, é necessário, no ato comunicativo, para que qualquer dos interlocutores possa contestar, de maneira fundamentada, através de argumentos, a pretensão de validade alheia.

Assim, a teoria da ação comunicativa revela profundo convencimento de Habermas quanto à capacidade linguística e cognitiva do ser humano, capaz de, no relacionamento discursivo, alcançar a verdade, consensualmente formada. É a predisposição ao entendimento mútuo das significações envolvidas, no contexto da interação comunicativa, a solução que Habermas defende para a reconstrução racional do ato de fala e, em decorrência, a superação das contradições da racionalidade instrumental (VIZEU, 2005).

A teoria do consenso da verdade, subjacente à noção de racionalidade comunicativa, envolve a capacidade de distinguir entre essência e aparência, isto é, de identificar as afirmações verdadeiras entre ser e ilusão e entre 
ser e dever. (HABERMAS, 1987). Para que ocorra a ação comunicativa e a verdade consensual seja obtida, Habermas entende que o ato de fala deve contemplar quatro requisitos: (a) veracidade - o que é dito deve ser verdadeiro; (b) sinceridade - a intenção explicitada deve ser autêntica; (c) retidão - as normas sociais a que se recorre devem ser válidas para todos os participantes; (d) inteligibilidade, isto é, a manifestação deve ser clara para todos (FORESTER, 1994; VIZEU e BIN, 2008).

Desta feita, a ação comunicativa pressupõe "[...] um ideal de consenso livre de coerção, e de compreensão e de acordo não manipulados" (FORESTER, 1994, p. 137). Isto evidencia o papel ideológico da dominação na manutenção de dada ordem social, pois, não manipulados e conscientes das evidências e justificativas discursivas adequadas, os indivíduos reuniriam condições de, livremente, aceitar a veracidade ou legitimidade de determinada postura ou fenômeno interveniente (FORESTER, 1994).

Dado que o ato de fala, para Habermas, é uma construção intersubjetiva de significados, de forma que há uma intenção para o agente da fala e uma interpretação para o ouvinte ou observador, a comunicação natural, fundamentada na racionalidade comunicativa, pressupõe, além do acordo comum quanto ao significado das proposições emanadas, um mecanismo específico de coordenação da ação e uma noção particular de reciprocidade (HABERMAS, 1990).

Isso porque, ao agir por intermédio da fala, o indivíduo pode emaranhar-se em dois tipos fundamentais de ação social linguisticamente mediada - ação monológica ou estratégica e ação dialógica ou comunicativa. Na primeira, a linguagem é meio de transmissão de informações. O sujeito, ao tratar o outro como objeto, intervém na realidade objetiva para a satisfação de seus anseios. Para Habermas (1987, p. 123), a ação estratégica ocorre "[...] quando no cálculo que o ator faz de seu êxito intervém a expectativa de decisões de ao menos outro ator que também atua com vistas à realização de seus próprios propósitos. Este modelo de ação é interpretado de forma estritamente utilitarista [...]".

Constituindo, portanto, uma forma de manipulação, seja consciente ou não, a ação monológica ou estratégica busca o acordo sem entendimento das pretensões dos interlocutores, ou seja, recorrendo a uma distorção comunicativa, ao deturpar os requisitos da veracidade, sinceridade, retidão e inteligibilidade. Não se vislumbra o acordo comum, mas sim o convencimento de uma das partes sobre a outra, em relação marcada pela assimetria de argumentos e de poder. A coordenação da ação social passa a depender da influência de um dos atores sobre o outro e sobre a situação contextual, isto é, concretiza-se mediante recursos não linguísticos (HABERMAS, 1990; VIZEU e BIN, 2008).

Na segunda - a ação dialógica ou comunicativa -, a linguagem é utilizada tanto como meio para transmissão de informação quanto como fonte de integração social. A própria pretensão de validade que permeia os discursos, em busca do consenso intersubjetivamente construído, basta para a coordenação da ação social. A relação linguística é travada entre sujeitos, não entre sujeito-objeto, dotada de uma intersubjetividade capaz de realizar a emancipação humana via interação social. Como destaca Habermas, a ação comunicativa

[...] se refere [sic] a interação de ao menos dois sujeitos capazes de linguagem e de ação que (já seja com meios verbais ou com meios extraverbais) entabulam uma relação pessoal. Os atores buscam entender-se sobre uma situação de ação para poder assim coordenar de comum acordo seus planos de ação e com ele suas ações. O conceito aqui central é o de interpretação, se refere primordialmente $[s i c]$ a negociação de definições da situação susceptível de consenso (HABERMAS, 1987, p. 124).

O uso da teoria da ação comunicativa nos estudos organizacionais, em consonância com a apropriação do referencial teórico pela Gestão Social, constitui opção para abordagens alternativas à orientação funcionalista dominante, em particular: (i) por levantar-se como corpo teórico útil ao entendimento da organização como locus de interações linguísticas entre sujeitos capazes e, em decorrência, à análise das distorções comunicativas presentes na prática gerencial tradicional (relação gerente-trabalhador, monológica) e no modelo organizacional dominante (burocracia e hierarquia, inibidoras da competência comunicativa); (b) por permitir a identificação e a sobreposição das restrições social e comunicativamente desnecessárias à 
cooperação social e à ação democrática, se entendidas como processos dialogicamente orientados (FORESTER, 1994; VIZEU, 2005).

\section{Os Contributos da Ecologia Profunda e da Gestão Social para a Discussão sobre Sustentabilidade Empresarial}

Estabelecida uma concepção mais coerente para o tratamento analítico da sustentabilidade empresarial - o paradigma da ecologia profunda -, e delineado um modo de gestão mais adequado a tal paradigma - a gestão social -, resta, por fim, a tarefa de pontuar os contributos de ambos - ecologia profunda e gestão social -, para a discussão sobre sustentabilidade empresarial. O intento será cumprido pela via da redução do conhecimento (RAMOS, 1965), mediante seis caracteres teórico-conceituais, não representando um rol taxativo, exaustivo, de se encarar a temática, mas, no âmago, constituindo uma incursão à sua essencialidade, permitindo, como advogava Ramos (1965), o posicionamento do sujeito participante como um sujeito, acima de tudo, cognoscente:

(a) a gestão social possibilita que a mediação entre homem e natureza, organização e recursos ecológicos seja pautada por uma forma de pensar e por um conjunto de valores marcados pelo caráter integrativo, cooperativo, qualitativo e de parceria (CAPRA, 2006), ao defender valores como a inclusão, a igualdade, o pluralismo, a autonomia e o bem comum, posicionando-se contra abordagens autoritárias e coercitivas, típicas da relação de dominação que tradicionalmente foi concebida entre homem e natureza;

(b) a gestão social, ao reconhecer a capacidade linguística e cognitiva do ser humano, capaz de, no relacionamento discursivo, alcançar a verdade, consensualmente formada, permite reconhecer no outro, humano ou qualquer fenômeno vivo, o princípio ecológico basilar - a interdependência -; em outras palavras, fomenta no homem a consciência de que comunidade humana e comunidade ecológica estão intrinsecamente relacionadas e que, portanto, o homem deve lidar com a natureza da mesma forma que trata com um semelhante seu, mediante o reconhecimento de que o outro não é objeto, mas sim sujeito;

(c) a gestão social, ao priorizar a dialogicidade em espaços sociais isentos de coerção e, portanto, de distorções comunicativas, possibilita que a produção e disseminação do conhecimento sobre sustentabilidade empresarial, em fóruns científicos e espaços acadêmicos, ocorra por intermédio de uma ação comunicativa - na qual os participantes, dentro de um procedimento argumentativo, estabeleçam acordo comum sobre questões vinculadas à verdade, justiça e autenticidade, formado com base numa pretensão de validade e necessário para que qualquer dos interlocutores possa contestar, de maneira fundamentada, através de argumentos, a pretensão de validade alheia - e não com base em imperativos inquestionáveis e relações de poder assimétricas;

(d) a gestão social representa alternativa crítica ao mainstream dominante nos estudos organizacionais, no qual o tema da sustentabilidade vem sendo apropriado, e, assim, possibilita nova abordagem à temática, ao permitir a identificação e a sobreposição das restrições social e comunicativamente desnecessárias à relação organização x natureza, à cooperação social e à ação democrática, se entendidas como processos dialogicamente orientados;

(e) o paradigma da ecologia profunda permite reconhecer a falácia implícita na ideia de que o homem é o legítimo proprietário dos recursos naturais e que, portanto, a discussão deve incidir estritamente sobre a forma de uso da natureza e dos reflexos daí decorrentes em relação à atividade produtiva humana, concebendo, em contrapartida, um novo paradigma em que o meio ambiente, assim como o homem, é também um sistema vivo que compartilha da mesma essencialidade, exigindo tratamento semelhante;

(f) o paradigma da ecologia profunda reconhece a incompletude da perspectiva economicista da sustentabilidade, reconhecendo na natureza um sistema vivo, assim como o homem, que, em decorrência, necessita de uma abordagem em que o cálculo utilitário de consequência seja 
complementado pela capacidade de "[...] pensar o mundo, de se pensar no mundo, de ter uma atividade racional e calculadora, mas também de pôr em questão a si mesmo e a seu meio ambiente" (GAULEJAC, 2007). Isso, por certo, exige uma abordagem dialógica, colaborativa e comunicativa, algo que a gestão social tem contributos a oferecer.

\section{Considerações Finais}

Este artigo, ao buscar resposta para a problemática - o que significa planejar estrategicamente para a sustentabilidade? -, procurou demonstrar a importância de se abordar o tema da sustentabilidade empresarial a partir de novas perspectivas teóricas, capazes de ampliar a tessitura analítica do arcabouço teórico dominante, de forte viés econômico. Desse ponto de vista, planejar estrategicamente para a sustentabilidade envolve um novo olhar crítico e reflexivo, dialógico e comunicativo, nas relações homem/homem, homem/organização, ambiente/organização e ambiente/homem.

Esse novo olhar, para a discussão esposada, circunscreveu-se ao paradigma da ecologia profunda e à noção de gestão social. Por certo, apenas alternativas, diante de inúmeras outras possibilidades de enfrentar a complexidade do tema sustentabilidade. Contudo, alternativas dignas de consideração e que merecem passar a permear os fóruns acadêmicos de produção e disseminação do conhecimento científico. Esse foi o intento principal do trabalho. Os contributos da ecologia profunda e da gestão social ao tema, expostos ao final das discussões, são apenas indicativos e subsídios provisórios para aprofundamentos acadêmicos futuros, frutos da dialogicidade humana.

\section{Referências}

ALMEIDA, F. O bom negócio da sustentabilidade. Rio de Janeiro: Nova Fronteira, 2002.

ASSOUN, P. L. A escola de Frankfurt. São Paulo: Ática, 1991.

BOYACIGILLER, N.; ADLER, N.J. The parochial dinosaur: organizational science in a global context. Academy of Management Review, v. 16, n. 2, april, p. 262-290, 1991.

BRUNDTLAND, G. H. (Coord.). Nosso futuro comum. 11. ed. Rio de Janeiro: FGV, 1991.

CALLENBACH, E. et al. Gerenciamento ecológico: eco-manangement. São Paulo: Cultrix, 1993.

CANÇADO, A. C. Fundamentos teóricos da gestão social. Tese de doutorado. Lavras: UFLA, 2011, 246 p.

; TENÓRIO, F.G.; PEREIRA, J. R. Gestão social: reflexões teóricas e conceituais. Cad. EBAPE.BR, v. 9, n. 3, set., p. 681-703, 2011.

CAPRA, F. A teia da vida: uma nova compreensão científica dos sistemas vivos. Cultrix: São Paulo, 2006.

CHANLAT, J.-F. Ciências sociais e management. Revista de Administração da FEAD, v. 3, n. 2, dez., p. 9-17, 2006.

CLARO, P.B.O.; CLARO, D.P.; AMÂNCIO, R. Entendendo o conceito de sustentabilidade nas organizações. Revista de Administração, v. 43, n. 4, out./dez., p. 289-300, 2008.

DONAIRE, D. Gestão ambiental na empresa. 2. ed. São Paulo: Atlas, 1999.

FORESTER, J. Teoria crítica e análise organizacional. Plural, v. 1, p. 131-148, 1994. 
FOURNIER, V.; GREY, C. At the critical moment: conditions and prospects for critical management studies. Human Relations, London, v. 53, n. 1, p. 7-32, jan., 2000.

FREIRE, P. Pedagogia da autonomia: saberes necessários à prática educativa. São Paulo: Paz e Terra, 2011.

FREITAG, B. A teoria crítica ontem e hoje. São Paulo: Brasiliense, 1986.

GAULEJAC, V. A ligação vale mais que o bem. In: GAULEJAC, V. Gestão como doença social: ideologia, poder gerencialista e fragmentação social. Aparecida (SP): Letras \& Ideias, 2007, p. 285-325.

GOULART, S. Uma abordagem ao desenvolvimento local inspirada em Celso Furtado e Milton Santos. Cad. EBAPE.BR, v. 4, n. 3, out., p. 1-15, 2006.

GROOT, I. de. Measurement of sustainability in coffee and cocoa. Utrecht: Institute for Sustainable Commodities (ISCOM), 2002.

HABERMAS, J. Teoría de la acción comunicativa. Madrid: Taurus, 1987. 2 v.

Pensamento pós-metafísico: estudos filosóficos. Rio de Janeiro: Tempo Brasileiro, 1990.

Mudança estrutural da esfera pública: investigações quanto a uma categoria da sociedade burguesa. Rio de Janeiro: Tempo Brasileiro, 2003.

JACOBS, M. Sustainable development: from broad rhetoric to local reality. In: CONFERENCE FROM AGENDA 21, Document n.493, 1 Dec. 1994, Cheshire. Proceedings... Cheshire: Cheshire County Council, 1995.

MATOS, O. C. F. A escola de Frankfurt: luzes e sombras do Iluminismo. São Paulo: Moderna, 1993.

NETO, L. M.; GARRIDO, P. O.; JUSTEN, C. E. Desenvolvendo o aprendizado em gestão social: proposta pedagógica de fomento às incubadoras sociais. Cad. EBAPE.BR, v. 9, n. 3, set., p. 828-845, 2011.

OLIVEIRA, V. A. R. de; CANÇADO, A.C; PEREIRA, J.R. Gestão social e esfera pública: aproximações teóricoconceituais. Cad. EBAPE.BR, v. 8, n. 4, dez., p. 613-626, 2010.

OLIVO, V.M.F.; MISOCZKY, M.C. As estratégias discursivas presentes na origem do referencial para o desenvolvimento sustentável: uma análise crítica do Relatório de Brundtland. In: ENCONTRO ANUAL DA ASSOCIAÇÃO NACIONAL DOS PROGRAMAS DE PÓS-GRADUAÇÃO EM ADMINISTRAÇÃO, 27, 2003, Atibaia. Anais... [Rio de Janeiro]: ANPAD, 2003. 1 CD-ROM. Área e número: POP 1757.

PAULA, A.P.P. de. Por uma nova gestão pública: limites e potencialidades da experiência contemporânea. Rio de Janeiro: FGV, 2007.

POLANYI, K. A grande transformação: as origens da nossa época. 6. ed. Rio de Janeiro: Campus, 2000.

RAMOS, A.G. A redução sociológica. Rio de Janeiro: Tempo Brasileiro, 1965.

REDCLIFT, M. Sustainable development: exploring the contradictions. London/New York: Melthuen, 1987.

REED, M. Teorização organizacional: um campo historicamente contestado. In: CLEGG, S.R.; HARDY, C.; NORD, W.R. (Orgs.). Handbook de estudos organizacionais. São Paulo: Atlas, 1998, p.61-98.

SACHS, I. Pensando sobre o desenvolvimento na era do meio ambiente: do aproveitamento racional da natureza para a boa sociedade. In: . Caminhos para o desenvolvimento sustentável. Rio de Janeiro: Garamond, 2000, p. 4764.

SANTOS, B. de S. Pela mão de Alice: o social e o político na pós-modernidade. São Paulo: Cortez, 1995.

Um discurso sobre as ciências. 15. ed. Porto: Edições Afrontamento, 2007. 
A gramática do tempo: para uma nova cultura política. 2. ed. São Paulo: Cortez, 2008.

SPANGENBERG, J.H.; BONNIOT, O. Sustainability indicators: a compass on the road towards sustainability. Paper n. 81. Wuppertal: Wuppertal Institute, 1998. 34p

TENÓRIO, F.G. Gestão social: uma perspectiva conceitual. Rev. Adm. Pública, v. 32, n. 5, set./out., p. 7-23, 1998.

(Re)visitando o conceito de gestão social. In: LIANZA, S.; ADDOR, F. (Org.). Tecnologia e desenvolvimento social e solidário. Porto Alegre: UFRGS, 2005, p. 39-57.

. A trajetória do Programa de Estudos em Gestão Social (Pegs). Rev. Adm. Pública, v. 40, n. 6, nov./dez., p. 1145-62, 2006.

. (Re)visitando o conceito de gestão social. In: SILVA JR. et al (Org.). Gestão social: práticas em debate, teorias em construção. Juazeiro do Norte: UFC, 2008, p. 39-57

Gestão social: uma réplica. In: RIGO, Ariadne S. Gestão social e políticas públicas de desenvolvimento: ações, articulações e agenda. Recife: Univasf, 2010, p. 53-59.

VALLE, C.E. do. Qualidade ambiental: ISO 14000. 4. ed. São Paulo: SENAC, 2002.

VIZEU, F. Ação comunicativa e estudos organizacionais. Revista de Administração de Empresas, v. 45, n. 4, out./dez., p. 10-21, 2005.

; BIN, D. Democracia deliberativa: leitura crítica do caso CDES à luz da teoria do discurso. Rev. Adm. Pública, v. 42, n. 1, jan./fev., p. 83-108, 2008.

WHITLEY, R. The fragmented state of management studies: reasons and consequences. Journal of management studies, v. 21, n. 3, july, p. 331-348, 1984. 